\title{
CORRECTION
}

\section{Correction to: Current concept in upright spinal MRI}

\author{
R. Botchu ${ }^{1}$ - A. Bharath ${ }^{1}$ - A. M. Davies ${ }^{1} \cdot$ S. Butt ${ }^{2} \cdot$ S. L. James ${ }^{1}$
}

Published online: 26 February 2018

c) Springer-Verlag GmbH Germany, part of Springer Nature 2018

\section{Correction to: Eur Spine J}

https://doi.org/10.1007/s00586-017-5304-3

Unfortunately, the legend of Fig. 5 was incorrectly published in original publication. The corrected legend is given below.

Fig. 5 T2 sagittal image of cervical spine in neutral (a) and extension (b) positions, showing mild central canal narrowing at $\mathrm{C} 5 / 6$ on extension which is not present on the neutral image.

The original article can be found online at https://doi.org/10.1007/ s00586-017-5304-3.

R. Botchu

rajesh.botchu@nhs.net

1 Department of Musculoskeletal Radiology, The Royal Orthopedic Hospital, Bristol Road South, Northfield, Birmingham B31 2AP, UK

2 Department of Musculoskeletal Radiology, Royal National Orthopaedic Hospital, Brockley Hill, Stanmore, Middlesex HA7 4LP, UK 